\title{
An Important Differential Diagnosis with Elevated D-Dimer: Acute Pulmonary Embolism or Aortic Dissection
}

\author{
Ekrem Şahan ${ }^{*}$ and Suzan Şahan ${ }^{2}$ \\ ${ }^{1}$ Cardiology, Atatürk Chest Disease and Thoracic Surgery Training and Research Hospital, Turkey \\ ${ }^{2}$ Cardiology, Turkiye Yuksek Ihtisas Training and Research Hospital, Turkey
}

*Corresponding author: Ekrem Şahan, MD, Cardiologist, Atatürk Pulmonary Disease and Thoracic Surgery Training and Research Hospital, Sanatoryum Street, 06280, Kecioren, Ankara, Turkey, Tel: +905333538832, Email: ekremsahan@hotmail.com

\begin{abstract}
Acute pulmonary embolism (APE) or acute aortic dissection is one of the most serious clinical presentations at emergency department. Chest pain and elevated serum D-dimer level can be found in both APE and AAD. Echocardiography can be used as first line imaging modality for differential diagnosis. Computed tomography angiography is the main diagnostic test for APE and AAD. We aimed to emphasize differential diagnosis of chest pain with this case report.
\end{abstract}

\section{Keywords}

Aortic dissection, Pulmonary embolism, D-dimer

\section{Case Report}

An elderly man aged 82 years who had hypertension for 22 years was admitted to the emergency department with severe chest and back pain. According to information gained from the patient, he has used regularly hypertension medical (perindopril + indapamide $4 / 1.25 \mathrm{mg}$ ) and he had no history of other chronic disease (cardiac disease, kidney disease, diabetes mellitus or connective tissue disorder), operations, or hospitalization. When he arrived at the hospital, his blood pressure was $140 / 70 \mathrm{mmHg}$, heart beat was 72 beats per minute, electrocardiography was normal, and D-dimer was high $(1390 \mathrm{ng} / \mathrm{mL})$. The patient was referred to our hospital with a diagnosis of pulmonary embolism. Transthorasic echocardiography (TTE) showed that the diameter of ascending aorta was nearly $10.3 \mathrm{~cm}$ (Figure 1) and, in the apical four chamber view decending aorta had dissection with true and false lumen (Figure 2). TTE revealed that his ejection fraction was $60 \%$ (used modified Simpson calculation), and there was minimal regurgitation of the aortic valve. Thoracal computed tomography angiography (CTA) showed type B aortic dissection (Figure 3). There was a aortic aneurysm that started from aortic valve and including the ascending aorta and there was a aortic dissection with clearly visible true and false lumen on the decending aorta. The diameter of ascending aorta was $92.9 \mathrm{~mm}$ on CTA. IV esmolol and sodium nitroprussid infusion was initiated and the patient was consulted with cardiovascular surgeon. Due to unwillingness of the patient's relatives and no malperfusion, thoracic endovascular aortic repair (TEVAR) or any surgical procedure was not performed.

\section{Discussion}

Acute pulmonary embolism (APE) is one of the most serious clinical presentations at emergency department associated with significant short- and long-term complications, and a mortality rate of $15-20 \%$ [1]. Suspected APE with shock or hypotension is a life-threading clinical problem and the differential diagnosis includes acute coronary syndrome (ACS), aortic dissection, tamponade or acute valvular dysfunction. The most useful initial test in this situation is transthorasic echocardiography [2]. Suspected APE without shock or hypotension, computed tomographic angiography (CTA) is the main thoracic imaging test but in the emergency department, plasma D-dimer measurement is the first diagnostic step and a normal D-dimer level allows to be ruled out APE diagnosis in around $30 \%$ of patients [3]. D-dimer levels are elevated in plasma with acute thrombosis as a result of coagulation and fibrinolysis.

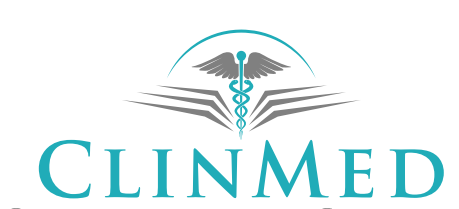

INTERNATIONAL LIBRARY

Citation: Ekrem S, Suzan S (2018) An Important Differential Diagnosis with Elevated D-Dimer: Acute Pulmonary Embolism or Aortic Dissection. Clin Med Rev Case Rep 5:216. doi.org/10.23937/2378-3656/1410216 Accepted: May 26, 2018: Published: May 28, 2018

Copyright: (C) 2018 Ekrem S, et al. This is an open-access article distributed under the terms of the Creative Commons Attribution License, which permits unrestricted use, distribution, and reproduction in any medium, provided the original author and source are credited. 


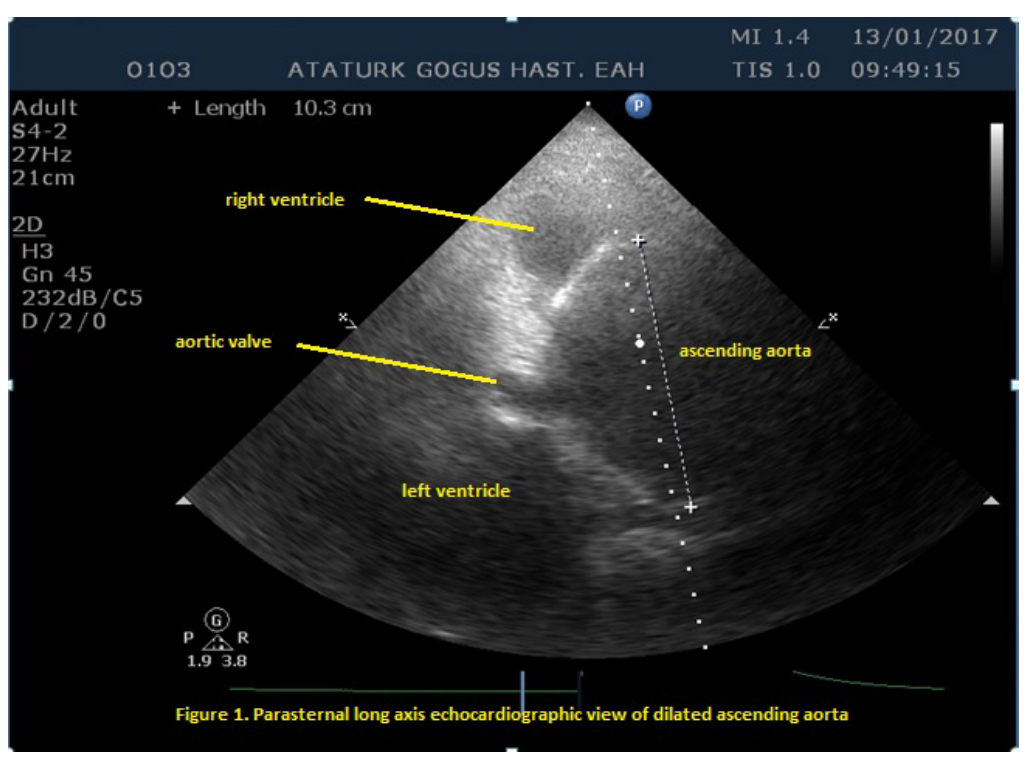

Figure 1: Parasternal long axis echocardiographic view of dilated ascending aorta.

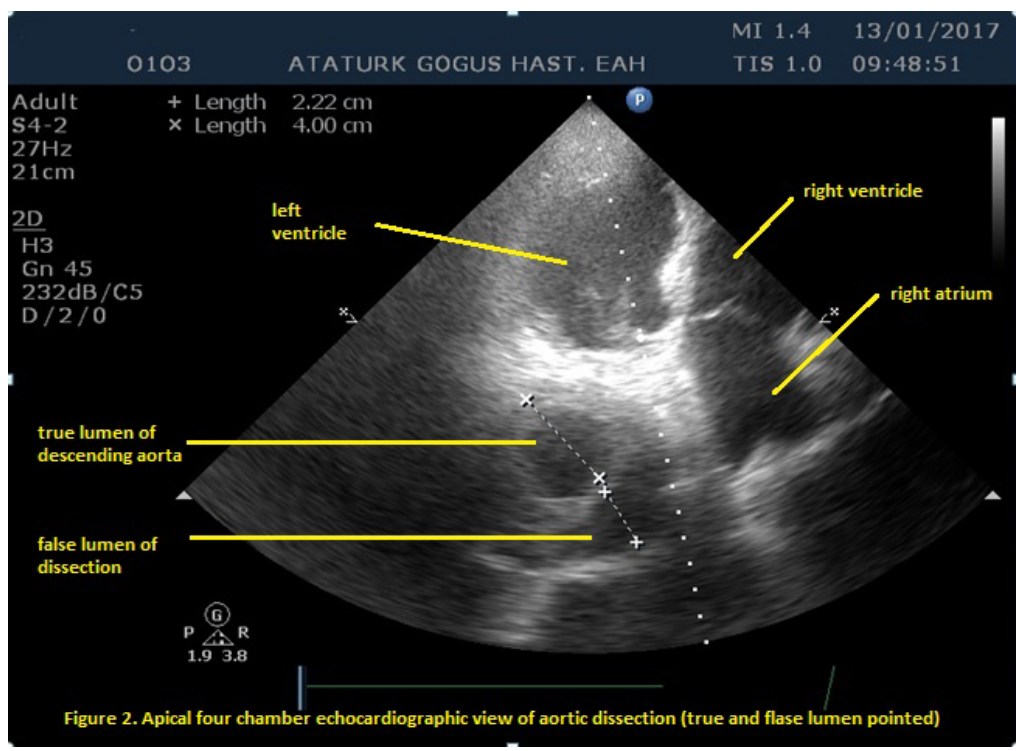

Figure 2: Apical four chamber echocardiographic view of aortic dissection (true and false lumen pointed).

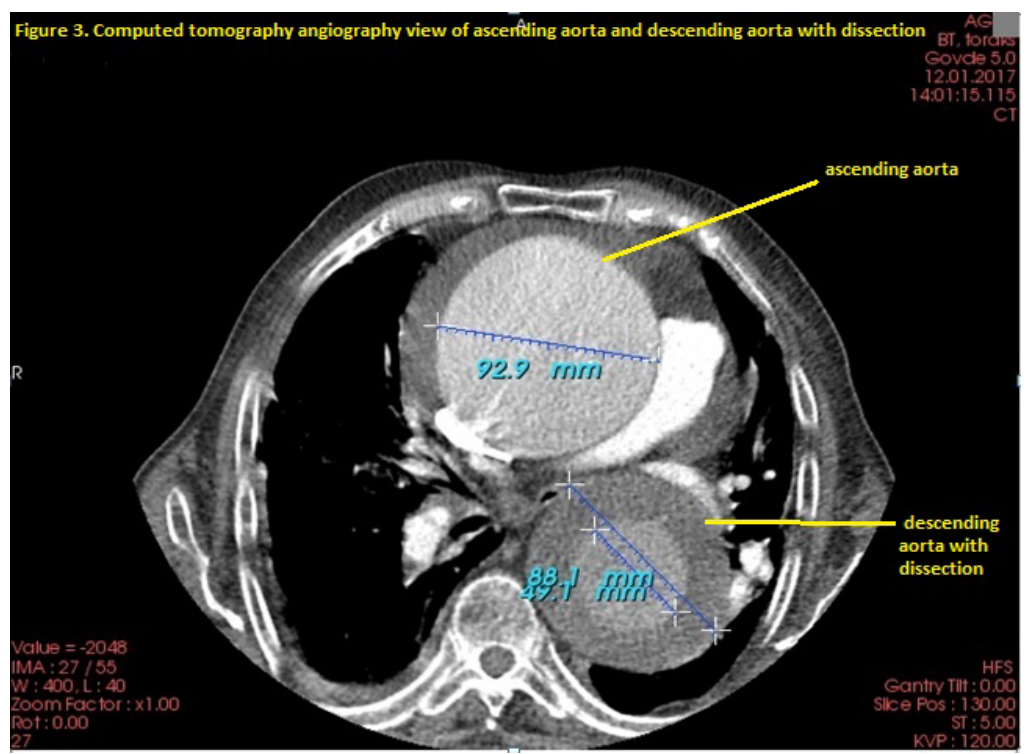

Figure 3: Computed tomography angiography view of ascending aorta and descending aorta with dissection. 
Aneurysm is the second most frequent disease of the aorta after atherosclerosis. Patients with thorasic aorta aneurysm are most often asymptomatic and the diagnosis is made incidentally with other investigative reasons or screening purposes. Surgical decision is based mainly on aortic diameter. Surgery should be performed in patients with Marfan syndrome, who have a maximal aortic diameter $\geq 50 \mathrm{~mm}$ [4]. With the diameter is 45 $\mathrm{mm}$, surgical decision can be considered in patients with additional risk factors, including family history of dissection, size increase $0.3 \mathrm{~mm} /$ year (in repeated examinations using the same technique and confirmed by another technique), severe aortic regurgitation, or desire for pregnancy [5].

Aortic dissection is defined as separation of the aortic wall layers and subsequent formation of a true lumen and a false lumen with or without communication. Generally, a tear in the intimal layer is the starting condition, results as a new track for the blood and the blood enters the intima-media space (false lumen). Aortic dissection classified Type $A$ (dissection includes asendan aorta) and Type $B$ (dissection includes decendan aorta-distal from left subclavian artery) [6]. For the Type A dissection, surgery is the only treatment choice. Acute Type A dissection has a mortality of $50 \%$ within the first 48 hours if not operated. Patients with uncomplicated (especially not caused malperfusion for visseral organs). Type B dissection must receive medical therapy to control pain, heart rate, and blood pressure. Thoracic endovascular aortic repair (TEVAR) is a treatment choice, aims stabilization of the dissected aorta [7]. The proximal intimal tear is obliterated by implantation of
TEVAR, blood flow is redirected to the true lumen. TEVAR is the treatment of choice in complicated acute Type B dissection [7].

\section{References}

1. Goldhaber SZ, Visani L, De Rosa M (1999) Acute pulmonary embolism: clinical outcomes in the International Cooperative Pulmonary Embolism Registry (ICOPER). Lancet 353: 1386-1389.

2. Roy PM, Meyer G, Vielle B, Le Gall C, Verschuren F, et al. (2006) Appropriateness of diagnostic management and outcomes of suspected pulmonary embolism. Ann Intern Med 144: 157-164.

3. Righini M, Aujesky D, Roy PM, Cornuz J, de Moerloose P, et al. (2004) Clinical usefulness of D-dimer depending on clinical probability and cutoff value in outpatients with suspected pulmonary embolism. Arch Intern Med 164: 2483-2487.

4. Jondeau G, Detaint D, Tubach F, Arnoult F, Milleron O, et al. (2012) Aortic event rate in the Marfan population: A cohort study. Circulation 125: 226-232.

5. Vahanian A, Alfieri O, Andreotti F, Antunes MJ, Baron-Esquivias G, et al. (2012) Guidelines on the management of valvular heart disease (version 2012). Eur Heart J 33: 2451-2496.

6. Reul GJ, Cooley DA, Hallman GL, Reddy SB, Kyger ER 3rd, et al. (1975) Dissecting aneurysm of the descending aorta. Improved surgical results in 91 patients. Arch Surg 110: 632-640.

7. Grabenwoger M, Alfonso F, Bachet J, Bonser R, Czerny M, et al. (2012) Thoracic Endovascular Aortic Repair (TEVAR) for the treatment of aortic diseases: a position statement from the European Association for Cardio-Thoracic Surgery (EACTS) and the European Society of Cardiology (ESC), in collaboration with the European Association of Percutaneous Cardiovascular Interventions (EAPCI). Eur Heart J 33: 1558-1563. 